\title{
Palatal Myoclonus (syn. Palatal Tremor)
}

\author{
J.M.S. Pearce \\ Emeritus Consultant Neurologist, Department of Neurology, Hull Royal Infirmary, Hull, UK
}

\section{Key Words}

Palatal tremor - Palatal myoclonus - Guillain-Mollaret triangle $\cdot$ Hypertrophic inferior olivary nucleus $\cdot$ Neuronal coupling

\section{Abstract \\ Symptomatic palatal tremor is caused by a lesion in the tri- angle of Guillain and Mollaret and is associated with hyper- trophic olivary degeneration that has multiple causes. Es- sential palatal tremor has no currently demonstrable cause and no accompanying physical or radiological signs. But it is probable that an organic genesis will become apparent. I suggest that some examples of palatal tremor may depend on an 'upper motor neurone type', i.e. supranuclear, lesion in the striatum or rostral brainstem releasing medullary activa- tion with denervation hypersensitivity of olivary neurones.}

Copyright $\odot 2008$ S. Karger AG, Base

\section{Case Report [1]}

In 1968 a retired ship worker aged 67 was admitted to the recently opened Hull Royal Infirmary (UK). For 12 months he had experienced typical recurrent episodes of cerebral ischaemia with motor and sensory defect in all limbs. His last attack was associated with double vision and ataxia. He had been treated for hypertension for 4 years.

On examination, his blood pressure was 190/110, equal in both arms. He had nystagmus on left lateral gaze and internuclear ophthalmoplegia with weakness of the right medial rectus. The remaining cranial nerves were normal except for the striking ap- pearance of myoclonus of the soft palate on the right side, consisting of involuntary movements with a rate varying from 120 to 180 per min. The lips, tongue, larynx and diaphragm were not involved. No carotid or subclavian bruit. His legs showed a mild spastic weakness with slight incoordination, and with exaggeration of all deep tendon reflexes. Both plantar responses were extensor; no sensory deficit. Routine laboratory investigations and CSF normal. (This was before CT and MRI.)

The diagnosis was of recurrent attacks of brainstem ischaemia causing palatal myoclonus (PM), based on a hypertensive vascular lesion [1] involving the medial longitudinal fasciculus and the Guillain-Mollaret triangle. He recovered without drug therapy apart from for his hypertension, but his PM persisted.

\section{History}

In 1886 H.R. Spencer (1860-1941) $)^{1}$ described myoclonic movements of the pharynx and larynx, and noted the similarity to nystagmus [2]. The inferior olivary nucleus ('the olive'), in certain pathological conditions, is apt to show a peculiar type of abnormality whose main feature is a conspicuous enlargement. Early references to such 'hypertrophy' of the olive are those of Oppenheim [3] in 1887, Thomas [4], and Marie and Guillain [5]. There was renewed interest in 1928 when van Bogaert and Ber-

\footnotetext{
1 Herbert Ritchie Spencer was Professor of Obstetric Medicine at University College, London. He gave the Harveian oration and Lettsomian and Fitzpatrick Lectures. He examined for both Royal Colleges (Munk's Roll, vol. IV, p. 416).
}

\section{KARGER}

Fax +41 613061234 E-Mail karger@karger.ch www.karger.com

\section{(C) 2008 S. Karger AG, Base \\ 0014-3022/08/0606-0312\$24.50/0}

Accessible online at:

www.karger.com/ene
J.M.S. Pearce

304 Beverley Road

Anlaby, East Yorks, HU10 7BG (UK) 
Table 1. Features of essential versus symptomatic palatal myoclonus

\begin{tabular}{|c|c|c|}
\hline & Essential PM & Symptomatic PM \\
\hline Main muscle involved & tensor veli palatini & levator veli palatini \\
\hline Other signs & no & $\begin{array}{l}\text { ocular and/or pharyngeal myoclonus, } \\
\pm \text { ataxic syndrome }\end{array}$ \\
\hline Ear clicking & infrequent & frequent \\
\hline Disappears in sleep & yes & no \\
\hline MRI & usually no lesion & medullary lesion \\
\hline Electrophysiology & abnormal polysynaptic brainstem reflexes & $\begin{array}{l}\text { abnormal monosynaptic, oligosynaptic } \\
\text { and polysynaptic reflexes }\end{array}$ \\
\hline
\end{tabular}

trand [6] showed the constant presence of these olivary changes in 'rhythmic and synchronous' PM.

Over the next 40 years, Guillain and Mollaret [7], Bender et al. [8], Nathanson [9] and many others reported small groups of patients with PM.

\section{Clinical Features}

Certain features separate this form of myoclonus from other varieties of myoclonus (table 1). Careful study in the above case report and in the patients described by Nathanson [9] have shown that the myoclonus can persists during phonation and sleep in symptomatic PM. Intravenous barbiturates which can abolish nystagmus do not affect PM, nor is it influenced by caloric stimulation, the inhalation of carbon dioxide or the advent of coma. It may persist indefinitely but is not a cause of disability, although patients may complain of a 'clicking' sound in the ear, made by the spasmodic contractions of the levator veli palatini part of whose origin is from the cartilaginous auditory tube. Associated disordered, synchronous eye movements include nystagmus, vertical and pendular or horizontal and torsional or hypermetropic saccades: so-called 'oculopalatal myoclonus'. PM may be also accompanied by synchronous contractions in the oropharynx, larynx, oesophagus and diaphragm.

\section{Aetiology}

The aetiology in about 70\% of cases has been a vascular infarct. Multiple sclerosis, metastatic and astrocytic tumours, syringobulbia, and trauma have been invoked as occasional causal lesions. Of 287 cases with PM from the literature $75 \%$ were symptomatic and no cause was found in the 25\% 'essential' cases. Myoclonic contractions are located in the levator veli palatini muscle (facial or nucleus ambiguus innervation) in symptomatic, and in tensor veli palatini (trigeminal innervation) in 'essential' cases. MRI may be normal, but a hyperdense signal in the region of the inferior olive on $\mathrm{T}_{2}$ or proton density images is often seen in symptomatic PM [10].

A heterogeneous syndrome of progressive ataxia with palatal tremor and dysarthria has been reported [11]. Rare instances of an association with Alexander's disease and Rosenthal fibre encephalopathy [12], supranuclear palsy, and, prominent bilateral activation of the putamen [13] have been associated with PM.

\section{Possible Mechanisms}

Palatal myoclonus (syn. palatal tremor) is of two types: symptomatic and essential. (1) Symptomatic palatal tremor is caused by a lesion in the triangle of Guillain and Mollaret and is associated with hypertrophic olivary degeneration visible on MR images. (2) Essential palatal tremor has no currently demonstrable cause, and no accompanying physical or radiological signs, and is almost certainly heterogeneous.

Experimental stimulation or destruction of the inferior olivary nucleus produces PM in the monkey. In 1931, Guillain and Mollaret [7] described anatomical features related to PM. These comprised the dentate nucleus, red nucleus and inferior olivary nucleus - referred to as the Guillain-Mollaret triangle (fig. 1) [14, 15]. The dentatorubral-olivary pathway comprises efferents from the dentate nucleus which ascend through the superior cerebellar peduncle, cross the midline in the brachium conjunctivum to the red nucleus, and descend via the central tegmental tract to the inferior olivary nucleus. Inferior olivary efferent fibres cross the midline in the inferior 


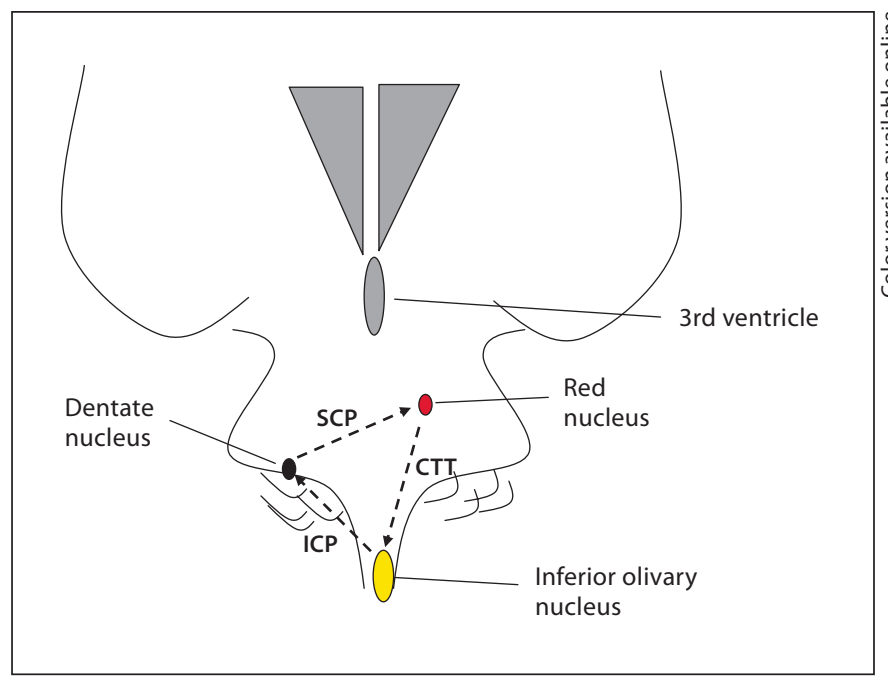

Fig. 1. Guillain-Mollaret triangle. SCP = Superior cerebellar peduncle; ICP = inferior cerebellar peduncle; CTT = central tegmental tract.

cerebellar peduncle, terminating in the original dentate nucleus (fig. 1) [16, 17].

In 1935, Julio Óscar Trelles (1904-1990), a neurologist from Lima, Peru, reported that isolated lesions of the inferior cerebellar peduncle do not cause PM because there are no direct connections between the inferior olive and the contralateral dentate nucleus. When damaged they were associated with olivary enlargement [17].

The site of the lesion is of interest. In all pathologically studied cases of symptomatic PM it has involved the dentate nuclei of the cerebellum, the central tegmental tract, and the inferior olivary nucleus [18] on the opposite side. The inferior olivary nucleus shows marked hyper- trophy $[19,20]$, usually after a delay of 1-6 months; palatal tremor may appear within days or after a delay of up to 30 months after an acute vascular lesion [21]. However, there are recorded instances of comparable olivary hypertrophy not accompanied by PM [21]. Hypertrophy of the olivary nucleus can result from transneuronal degeneration caused by any lesion of the ipsilateral central tegmental tract, the contralateral superior cerebellar peduncle or the dentate nucleus.

The inferior olivary nucleus receives a GABA-ergic input densely concentrated in the $\beta$-nucleus. The GABAergic system inhibits electronic coupling of inferior olivary neurons, and if disrupted may result in hypersynchronous firing of these polysynaptic neurons. This may derive from putaminal, ipsilateral brainstem or contralateral cerebellar lesions, with resulting PM. The neurons of the olive are extensively coupled by gap junctions ('connexons'), which may relate to their capacity to oscillate when there is loss of normal GABA-ergic inhibition [22]. Speculations of the mechanism consider interruption of inhibitory projections from the deep cerebellar nuclei, via the central tegmental tract, to the inferior olive. Blockade of cerebellar inhibition is followed by olivary hypertrophic degeneration with the development of connexons between cell bodies, causing synchronized oscillation of large groups of inferior olivary nucleus neurons. The synchronized signal is sent to the cerebellar cortex via climbing fibres, producing oscillations [23]. Symptomatic PM and its persistence result from denervation hypersensitivity of olivary neurones starting 1-2 months after the onset, because of the inhibitory blockade.

I suggest that essential palatal tremor may depend on an 'upper motor neurone type', i.e. supranuclear, lesion in the striatum or rostral brainstem releasing activation with denervation hypersensitivity of olivary neurones.

\section{References}

1 Pearce JMS: Palatal myoclonus. Proc R Soc Med 1969;62:267.

-2 Spencer HR: Pharyngeal and laryngeal 'nystagmus'. Lancet 1886;2:702-704.

3 Oppenheim H: Über Olivendegeneration bei Atheromatose der basalen Hirnarterien. Berl Klin Wochenschr 1887;34:638-639.

4 Thomas A: Recherches sur le faisceau longitudinal postérieur. Rev Neurol 1903;2:9496.

5 Marie P, Foix C: Sur la dégénération pseudohyperthrophique de l'olive bulbaire. Rev Neurol (Paris) 1913;26:48-52.
6 van Bogaert L, Bertand I: Sur les myoclonies associées synchrones et rythmiques par lésion en foyer du tronc cérébral: nouvelle observation anatomoclinique. Rev Neurol 1928;I:202-214.

7 Guillain G, Mollaret P: Deux cas de myoclonies synchrones et rythmées vélo-pharyngolaryngo-oculo-diaphragmatiques: le problème anatomique et physio-pathologique de ce syndrome. Rev Neurol (Paris) 1931;2:545566.

8 Bender MB, Nathanson M, Gordon GG: Myoclonus of muscles of the eye, face and throat. Arch Neurol Psychiatry 1952;67:44-58.
9 Nathanson M: Palatal myoclonus: further clinical and pathophysiological observations. Arch Neurol Psychiatry 1956;75:285296.

10 Deuschl G, Toro C, Valls-Solé J, Zeffiro T, Zee DS, Hallett M: Symptomatic and essential palatal tremor. 1. Clinical, physiological and MRI analysis. Brain 1994;117:775-788.

11 Samuel M, Torun N, Tuite PJ, Sharpe JA, Lang AE: Progressive ataxia and palatal tremor (PAPT): clinical and MRI assessment with review of palatal tremors. Brain 2004; 127:1252-1268. 
12 Howard RS, Greenwood R, Gawler J, et al: A familial disorder associated with palatal myoclonus, other brainstem signs, tetraparesis, ataxia and Rosenthal fibre formation. J Neurol Neurosurg Psychiatry 1993;56:977-981.

13 Haller S, Winkler DT, Gobbi C, Lyrer P, Wetzel SG, Steck AJ: Prominent activation of the putamen during essential palatal tremor: a functional MR imaging case study. Am J Neuroradiol 2006;27:1272-1274.

14 Guillain G, Molleret P, Bertrand I: Sur la lésion responsable du syndrome myoclonique de tronc cérébral. Rev Neurol (Paris) 1933; 666-674.
5 Gerace C, Fele MR, Luna R, et al: Bilateral hypertrophic olivary degeneration. J Neurol Neurosurg Psychiatry 2006;77:73-76.

16 Trelles JO: L'hypertrophie des olives bulbaires; thèse de médecine, Paris, 1935.

17 Trelles JO: La oliva bulbar: su estructura funcion y patologia. Rev Neuro-Psiquiatr 1943;6:433-521.

18 Gautier JC, Blackwood W: Enlargement of the inferior olivary nucleus in association with lesions of the central tegmental tract or dentate nucleus. Brain 1961;84:341-361.

19 Salamon-Murayama N, Russell EJ, Rabin BM: Diagnosis please. Case 17: hypertrophic olivary degeneration secondary to pontine hemorrhage. Radiology 1999;213:814-817.

20 Venturi F, Tampieri D, Brassard R, et al: Hypertrophic olivary degeneration (HOD): an unusual way to degenerate. Neuroimage 2001;17:7-8
21 Nishie M, Yoshida Y, Hirata Y, Matsunaga M: Generation of symptomatic palatal tremor is not correlated with inferior olivary hypertrophy. Brain 2002;126:1348-1357.

22 Mugnaini E, Nelson BJ: Corticotropin-releasing factor (CRF) in the olivo-cerebellar system and feline olivary hypertrophy; in Strata P (ed): The Olivocerebellar System in Motor Control. Berlin, Springer, 1989, pp 187-197.

23 Leigh RJ: Ocular oscillations and the inferior olive: glucose utilization and symptomatic ocular myoclonus. Neurology 2006;67:3. 